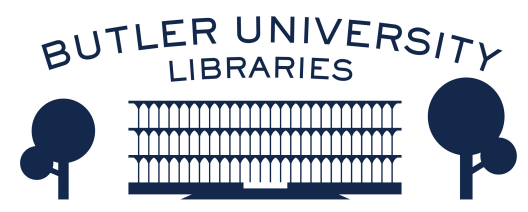

Journal of Hindu-Christian Studies

\title{
Yoga, Christians Practicing Yoga, and God: On Theological Compatibility, or Is There a Better Question?
}

Andrea R. Jain

Indiana University-Purdue University Indianapolis

Follow this and additional works at: https://digitalcommons.butler.edu/jhcs

Part of the Christianity Commons, and the Religious Thought, Theology and Philosophy of Religion Commons

\section{Recommended Citation}

Jain, Andrea R. (2017) "Yoga, Christians Practicing Yoga, and God: On Theological Compatibility, or Is There a Better Question?," Journal of Hindu-Christian Studies: Vol. 30, Article 6.

Available at: https://doi.org/10.7825/2164-6279.1658

The Journal of Hindu-Christian Studies is a publication of the Society for Hindu-Christian Studies. The digital version is made available by Digital Commons @ Butler University. For questions about the Journal or the Society, please contact cbauman@butler.edu. For more information about Digital Commons @ Butler University, please contact digitalscholarship@butler.edu. 
Jain: Yoga, Christians Practicing Yoga, and God: On Theological Compati

\section{Yoga, Christians Practicing Yoga, and God: On Theological Compatibility, or Is There a Better Question?}

\section{Andrea R. Jain \\ Indiana University-Purdue University Indianapolis}

HOUSTON is a wildly diverse city; nonetheless it should come as no surprise that the Houston Chronicle "Belief" section frequently features stories about church expansions or declines, pastoral developments, and other reports on Christian communities. Christians, after all, make up over $70 \%$ of the city's population. A provocative cover of a 2011 Belief section, however, shed light on a very different face of religion in Houston. The cover featured an image of local yoga teacher and entrepreneur Jennifer Buergermeister donning fashionable yoga attire and in the posture of a South Asian goddess, complete (thanks to clever photography) with six arms. The headline read, "THE SOUL OF YOGA." In the article, journalist Shellnutt quotes Buergermeister on how yoga helped her connect with "God as a creator, as a source" and brought her "closer to my divinity." Another local yoga teacher and entrepreneur,
Roger Rippy, was also interviewed for the article and is quoted denying that yoga is a religion because it is not based in dogma, but it is, nonetheless, "about your own particular practice and your own particular relationship with God."1

Some of the most influential yoga teachers and entrepreneurs speak of God in the context of yoga practice. World-renowned Ashtanga Yoga teacher and entrepreneur Kino Macgregor speaks frequently in public forums about her relationship with God and once described teaching yoga as "the one thing that God put [her] on this Earth to do."

All of this testifies to the lived reality that, although commercial yoga is often assumed to be a form of physical fitness distinct from theology or religion, it is frequently and explicitly linked to some envisioning of God in the imaginations of industry leaders and serious

Andrea R. Jain is Associate Professor of Religious Studies at Indiana University-Purdue University Indianapolis, editor of the Journal of American Academy of Religion, and author of Selling Yoga: From Counterculture to Pop Culture (Oxford University Press, 2014). She received her doctoral degree in religious studies from Rice University in 2010. Her areas of interest include contemporary spirituality and the history of modern yoga; the intersections of gender, sexuality, and yoga; religion and politics in contemporary society; and methods and theories in the study of religion. She is a regular contributor to Religion Dispatches on topics related to yoga in contemporary culture and Co-Chair of the Yoga in Theory and Practice Group of the American Academy of Religion. 
practitioners even when those practitioners are white bourgeois consumers buying and selling yoga for the widely lauded physical and health purposes of the modern commercial practice.

All that goes without even referencing those cases of commercial yoga that have explicit religious identities and commitments. There are now Christian yoga brands founded by Protestant Christians, such as Yahweh Yoga and Christ Centered Yoga. The website for Holy Yoga, based in Michigan and created by Brook Boon, describes it as "a community of believers on mission to bring the Gospel to the ends of the earth through the modality of yoga." ${ }^{3}$ Holy Yoga has an instructor training program, and there are hundreds of Holy Yoga classes each week in locations across the United States and Canada.

Many forms of Christian yoga often assign Christian terms and prayers to certain yoga postures or sequences and replace South Asian imagery, such as the popular "Om" symbol, with Christian imagery, such as the cross. Other forms, such as WholyFit and PraiseMoves, remove all explicitly yogic language and imagery, including the term yoga itself, to avoid associations with yoga's historical connections to other religions, especially Hinduism. Laurette Willis, a public speaker and fitness trainer, promotes PraiseMoves, for example, as "the Christian alternative to yoga." ${ }^{4}$

Some Catholics also teach yoga as a Christian practice. The Reverend Anthony Randazzo, a priest at Notre Dame Roman Catholic Church (North Caldwell, New Jersey) and co-author of Beatitudes, Christ and the Practice of Yoga, has practiced and taught yoga for years and insists that it has always brought him closer to God. ${ }^{5}$ Catholic priest Thomas Ryan is the director of the Paulist North American Office for Ecumenical and Interfaith Relations and a certified yoga instructor. He has also authored Prayer of Heart and Body: Meditation and Yoga as Christian Spiritual Practice. ${ }^{6}$

Christian yoga is not just an American thing. Indian Catholic priest Joseph Pereira has written about Christian yoga for Indian audiences, wrote a book and produced a DVD titled Yoga for the Practice of Christian Meditation, and founded the Kripa Foundation in India, which uses yoga as one component of recovery and support for people suffering from alcohol or drug addiction as well as those suffering from HIV and AIDS.?

Stephanie Corigliano, Bradley Malkovsky, and Michael Stoeber all offer varying ruminations on Hindu and Christian perspectives on God in/of/for/against yoga. Although Corigliano describes some Christian appropriations of yoga, the authors are generally more concerned with exploring the question: "Is the practice of yoga compatible with a Christian conception of God?" than with the question of how and why Christians appropriate yoga and put it to various religious purposes. In asking about compatibility, the articles respond-explicitly in Stoeber's article and implicitly in Malkovsky and Corigliano's articles-to those who court fear of commercial yoga, warning that Christians should not treat yoga as just another consumer product meant to meet individualized needs for self-care, because it is, in fact, religious and, more specifically, Hindu. Arguments against the theological compatibility between yoga and Christianity flourish in direct proportion to the industry's growth. Yoga, according to these arguments, is incompatible with Christian theology. Varying articulations of the argument that Christianity and yoga are incompatible pivot around an attempt to define yoga by locating some 
monolithic "center" or essence, especially one that defines yoga as Hindu.

They entail a preponderance of Hindu and Christian perspectives on where God is (or is not) in yoga, but they all agree that most practitioners of yoga, with their fitness- and consumer-based approach, are blind to what yoga really is, that is, a Hindu theological and ritual system. Christian protesters (who represent what I have called the Christian yogaphobic position) warn about the dangers of yoga given the perceived incompatibility between its so-called Hindu essence and Christian theology. ${ }^{8}$ Hindu protesters (what I have called the Hindu origins position) criticize commercial yoga for failing to recognize yoga's Hindu origins (which are perceived to be in conflict with Christian theology) and illegitimately appropriating and commodifying yoga for the sake of profit.

In my discussions of these arguments, I have rejected them, suggesting they are strikingly similar insofar as they are polemical, prescriptive, and share Orientalist and revisionist historical strategies. In other words, I suggest they are wrong, that there is nothing essentially Hindu about yoga, and there is no essential notion of God in yoga nor does yoga exclude any particular notion of God. Yoga has historically taken many forms, including countless that require devotion toward God (conceived in various ways) and countless that do not.

Corigliano, Malkovsky, and Stoeber offer different challenges to the Christian yogaphobic position and the Hindu origins position, arguing for the compatibility between Christianity and yoga by honing in on specific understandings and applications of yoga. Basically, they all offer some form of the following argument: "If by yoga, a person means $\mathrm{X}$, then yes, yoga and Christianity are compatible."

Like arguments against Christian yoga or Christians practicing yoga, which are premised on the assumption that yoga is or has been a static tradition that in all cases has featured various symbols, practices, and ideas that are in conflict with Christianity, the argument that some forms of yoga are compatible with Christian theology poses a problem insofar as it encourages an essentialist approach to conceptualizing yoga, Christianity, and Christian and yogic theologies. Yoga, however, has never belonged to any one religion, but has always been packaged in a variety of ways. This is the problem with the question of whether or not Christian theology is compatible with yogathere has never been one authentic or static yoga system and certainly no pervasive yogic theology.

The difference in my response to the question of compatibility as compared to those Corigliano, Stoeber, and Malkovsky offer is probably a matter of our scholarly lenses. Corigliano and Malkovsky are trained in theology and Stoeber in philosophy of religion, whereas my training is in the history of religions and critical theory. My inclination then has been to ignore or bracket the call to establish or verify claims about the legitimacy of Christians practicing yoga or the compatibility between Christian theology and yoga. It has been, instead, to acknowledge those claims, to analyze them as religious ones, and to critique them as conduits of certain social and political agendas.

on the one hand, theological discussions about religious complexes, such as yoga or Christianity, and concepts, such as God or prayer, are essentialist insofar as they identify definitional boundaries to these concepts' 
meanings. This frees the person to answer the question of yoga's compatibility or noncompatibility with Christianity. For example, a person might suggest, "If by yoga, you mean 3HO/Kundalini Yoga, then yes, yoga and Christianity are compatible because their conceptions of God overlap."

On the other hand, in narrowing down what a person means by yoga-for example, the yoga of Krishnamacharya (Corigliano), the yoga of the Yoga Sutras (Malkovsky), or the yoga of 3HO/Kundalini Yoga (Stoeber)-a person does not actually answer the question of whether or not yoga and Christianity are compatible in the lives of most of those Christians who practice yoga. Therefore, to suggest in response to the question of compatibility "If by this you mean that," means nothing to most Christians who are the subjects of criticism and even condemnation on the part of those offering up versions of the Christian yogaphobic position or the Hindu origins position. The fact is most of the Christians practicing yoga today are not reading Krishnamachary's Yoga Makaranda, studying the Yoga Sutras, or practicing 3HO/Kundalini Yoga. So when these authors speak of Christian yoga, Christians practicing yoga, or the compatibility between Christianity and yoga, they are speaking about very few Christians who actually practice yoga. In so doing, Corigliano, Malkovsky, and Stoeber's arguments about yoga's compatibility with Christianity imply that those Christians who practice yoga differently than the yoga systems under discussion might be violating their commitments to Christian theology.

My primary concern in reflecting on and responding to the pervasiveness of God in yoga discourses and in the articles under discussion is with avoiding offering up yet another representation that is out of touch with historical reality, instead mirroring in problematic ways the essentialist arguments of critics who suggest Christians should not practice yoga. Consumers and critics alike tend to reify yoga traditions in ways that simplify them and make them easier to contain, own, discuss, buy, or sell. It is more constructive, however, to focus on how discourses around God are produced by and meet the needs of and even privilege certain voices while not meeting the needs and sometimes silencing others than to argue on behalf of what is perceived as an historical precedent for or legitimate mode through which Christians can practice yoga without violating their theological commitments.

The problem, in other words, is that any limitation on the definition of yoga advanced in response to the question of whether yoga is compatible with Christian theology is open to an almost infinite variety of counterexamples that exemplify something that could in some sense plausibly be considered yogic, but which the proposed definition or discussion fails to include. So the minute the argument for yoga and Christian theology's compatibility is delineated based on a definition of yoga according to the Yoga Sutras, for example, the natural response is to say something like, what about hot yoga or vinyasa flow, some of the most common forms of yoga found in the commercial industry? As long as we imagine there are such things as essences when it comes to complex cultural products and concepts like yoga or Christianity, then a single counter-exampleand the majority of Christians practicing yoga would serve as counterexamples to the articles under discussion-to a proposed definition suffices to severely challenge its relevance to 
larger social and political debates about the place of yoga or lack thereof in Christian lives.

I am not suggesting, as an alternative, we include every imaginable counterexample of yoga in order to yield a definition of yoga so inclusive and unwieldy as to be useless. And I concede that the tantalizing temptation to reject the argument that Christians somehow violate their commitment to Christian theology when they practice yoga can drive the pursuit to identify moments of theological compatibility. That said, as long as one works with a definition of yoga that echoes an essentialist one offered by a particular tradition, guru, or text, the majority of Christian yoga practitioners will be left out of one's answer to the question, "Is yoga and Christianity compatible."

The pursuit to answer that question is finally coherent only if there is such a thing as the essence of yoga or Christianity, otherwise, a person is simply arguing, "In the extremely unusual case that a Christian practices yoga according to the teachings of Y (e.g., the Yoga Sutras, Krishnamacharya, or 3HO/Kundalini Yoga), then that person's Christian theological commitments are compatible with her yogic ones." And, in response, I think it reasonable to ask, "Why focus on this particular case of yoga and not this other case when responding to claims regarding Christianity and yoga's theological compatibility or lack thereof?"

In dealing with the question of yoga and Christianity's compatibility or incompatibility, I would encourage consideration of Peter Berger's suggestion that a definition is not more or less true but more or less useful. ${ }^{9}$ A definition's value, accordingly, can be measured in relation to its usefulness given some purpose. I would also push us in a non-essentialist, polythetic direction in the sense that a concept's meaning is best understood when one pays attention to the ways communities use that concept..$^{10}$ In other words, because language is public and social, so too is the meaning of words. A concept's meaning can be understood by attending to the way that concept is used in our practices, linguistic and otherwise. Yoga and Christianity, like religion, are meaningfully and correctly deployed in a variety of distinct contexts to identify different things. As usage and context vary, so too does meaning.

We rely on such distinguishing and reified categories as yoga and Christian to think about what are perceived as identifiable religions and religious boundaries, but those terms are far more fluid, contested, and unstable in their applications among yoga practitioners. In essentialist approaches to addressing the role of god in Christian yoga or among Christians who practice yoga, a person is bound to fail to delineate the role of God in a way that is consistent with that found among most Christians doing yoga. The historical deposit of Christians practicing yoga demonstrates that yoga cannot be judged as compatible or incompatible with Christian theology relative to some essentialized conception of yoga or Christianity. They must be understood instead in terms of the collective and divergent meanings and functions different yogic communities attribute to them.

This does not mean that yoga can mean whatever someone wants it to mean. Given how human beings talk about yoga in the present and historically, it is incorrect to say that yoga involves stepping into the bathtub and washing oneself. The polythetic view, therefore, is not to be confused with a relativist view-"Yoga just means whatever anyone says it means." We can say, however, that yoga is what yoga 
communities say it is. A polythetic view accounts for the multiple meanings that yoga has for different communities. Different uses of yoga, by dint of the way language works and changes, typically have some family resemblance to one another even if there might be truly different senses. We can accept this polythetic approach without embracing the absurd, unhelpful idea that yoga means both everything and anything and nothing at all. In other words, a word comes to mean something when a community of people link that usage with a sufficient collection of precedent usages and underlying practices, texts, or traditions so that this usage is a part of what that community means in describing themselves as yoga practitioners or describing some practice as yogic.

Given the multiplicity of usages, the countless things to which yoga has been and can be applied, yoga and its cognates (yogic etc.) have complex and multifaceted, not singular or essentialist, meanings. To the question, "Is yoga compatible with Christianity?" one response is

\section{Notes}

${ }^{1}$ Kate Shellnutt, "Practicing Yoga, Practicing Faith?" Houston Chronicle (February 25, 2011): F6-7.

${ }^{2}$ Kino MacGregor, "Confessions of a Loved and Hated Ashtangi," Elephant Journal (February 5, 2013), https://www.elephantjournal.com/2013/02/confess ions-of-a-loved-hated-ashtangi-kino-macgregor/.

${ }^{3}$ Holy Yoga, https://holyyoga.net.

${ }^{4}$ PraiseMoves, http://praisemoves. com/.

5 Anthony Randazzo and Madelana FerraraMattheis, Beatitudes, Christ and the Practice of Yoga: A Sacred Log on Land and Sea (Totowa, New Jersey: Resurrection Press, 2006).

6 Thomas Ryan, Prayer of Heart and Body: Meditation and Yoga as Christian Spiritual Practice (New York: Paulist Press, 1995).

${ }^{7}$ Kripa Foundation, www. kripafoundation.org. the following: "It depends on what you mean by yoga. If you mean $\mathrm{X}$-which is not a widely used meaning-in fact, it's extremely unusual-then yes." But we cannot settle whether $\mathrm{X}$ is the true definition of yoga, nor can we come to conclusions on other-more or less legitimateforms of yoga and their compatibility with Christianity. Any dispute about which is rightwhich conception of yoga or Christianity answers to the true essence of them-quickly becomes religious or theological in character, for it becomes a dispute about what truly betrays the essence of Christianity or yoga.

When much of what we say about yoga's compatibility with Christian theology is specific to such a narrow group as those Christians reading the Yoga Sutras then we betray much more about that narrow group than about yoga as it is a lived practice among the majority of Christians practicing it. We, therefore, do very little to respond to the historically misguided and politically charged articulations of the Christian yogaphobic position or the Hindu origins position.

${ }^{8}$ I have written elsewhere on these debates. See, for example, "The Malleability of Yoga: A Response to Christian and Hindu Opponents of the Popularization of Yoga," Journal of Hindu-Christian Studies 25 (2012): 310; "Who Is to Say Modern Yoga Practitioners Have It All Wrong?: On Hindu Origins and Yogaphobia," Journal of the American Academy of Religion 82(2) (June 2014): 427-471; and "Yogaphobia and Hindu Origins," Selling Yoga: From Counterculture to Pop Culture (New York: Oxford University Press, 2014): 130-157.

${ }^{9}$ Peter Berger, The Sacred Canopy: Elements of a Sociological Theory of Religion (New York: Doubleday, 197): 175.

10 On a polythetic approach, I draw on Wittgenstein and his concept of family resemblance (Ludwig L. Wittgenstein, Philosophical Investigations 
Jain: Yoga, Christians Practicing Yoga, and God: On Theological Compati

52 Andrea R. Jain

(Oxford: Blackwell, 1953)). See also my discussion on Counterculture to Pop Culture (New York: Oxford defining yoga in the conclusion of Selling Yoga: From University Press, 2014): 158-173. 